\title{
The Role of Botulinum Injection in Parkinson's Disease
}

\author{
Qamar Zaman* and Muhammad Farhan Khan \\ Department of Neurology, Shifa International Hospital, Shifa Tameer-e-milat university, Pakistan
}

Submission: January 08, 2019; Published: March 28, 2019

*Corresponding author: Qamar Zaman, Department of Neurology, Shifa International Hospital, Pitras Bukhari Road, H-8/4, Islamabad, Pakistan

\begin{abstract}
Botulinum toxin inhibits the release of acetylcholine at the neuromuscular junction, there by blocking neuromuscular conduction and muscle contraction. The mechanism of action of its various serotypes, are similar in respect that all of them cleave the SNARE proteins. It has been successfully used to treat a variety of symptoms related to Parkinson's disease including cervical dystonia, foot dystonia, focal hand dystonia, laryngeal dystonia, oromandibular dystonia, blepharospasm, lid apraxia, camptocormia, hand and jaw tremor, sialorrhea, hyperhidrosis, dysphagia, constipation, and overactive bladder. We did the review of the literature to find out the benefit observed with it, units used, and muscle selected for different indications in various studies done. This might help to determine the important issues related to Parkinson's disease where its application may be beneficial and also to pave a way for future recommendations.
\end{abstract}

Keywords: Botulinum; Dystonia; Siallorhea; Camptocormia; Blephrospasm

Abbreviations: PD: Parkinson's Disease; BoNT: Botulinum Toxin; FD: Foot Dystonia; FDL: Flexor Digitorum Longus; EHL: Extensor Hallus Longus; CD: Cervical Dystonia

\section{Introduction}

Clostridium botulinum is the bacterium that releases the most potent neurotoxin known and is responsible for causing botulism. There are seven different serotypes of $\mathrm{C}$. botulinum (A-G), but only the serotypes A, B, and E cause human botulism via colonization of the lower GI tract after ingestion of contaminated food. Botulism can present as muscle weakness, paralysis, dysarthria, dysphagia, constipation, and urinary retention. Death can occur in up to 10-25\% of cases. It has got use in various neurological disorders like spasticity, dystonia, hemifacial spasm, migraine and several nonneurological specialties like cosmetics, GI tract and GU tract disorders and ophthalmology [1]. Parkinson's Disease (PD) is a progressive, neurodegenerative disorder with pathological hallmark being the degeneration of dopaminergic neurons in the substantia nigra pars compacta and the presence of alpha synuclein-positive neuronal inclusions in several motor and non-motor brain circuits. It is a disorder marked not only by the motor features but also the presence of non-motor symptoms including sleep disorders, fatigue, pain, urinary dysfunction, constipation, sialorrhea, cognitive dysfunction, and depression/ anxiety [2-5]. Botulinum toxin (BoNT) has been successfully used to treat a variety of symptoms related to PD including cervical dystonia, foot dystonia, focal hand dystonia, laryngeal dystonia, oromandibular dystonia, blepharospasm, lid apraxia, camptocormia, hand and jaw tremor, sialorrhea, hyperhidrosis, dysphagia, constipation, and overactive bladder3. Here overview off its role for various important indications is given below.

\section{Role of botulinum in foot dystonia}

Various clinical features of Foot Dystonia (FD) are observed in Idiopathic Parkinson's Disease (IPD), ranging from simple forms such as inversion or hallux extension, to complex forms combining inversion, plantar and toe flexion, intra rotation, and dorsal and hallux extension. FD can occur in the morning before the first dose of levodopa has been taken and/or during daily off-periods, but also, during on-periods [4]. In a doubleblind randomized trial, two injection sites (Flexor digitorum longus vs. Flexor digitorum brevis) in lower limb muscles were compared at baseline and after 6,12 and 18 weeks. The primary outcome measure was the improvement of the patient's clinical state evaluated by the Clinical Global Impression of change (CGI) and Burke-Fahn-Marsden (BFM) Scale. Patients treated by botulinum toxin A showed a moderate improvement with a CGI score of $3.14 \pm 0.22$ at 6 weeks and $2.90 \pm 0.20$ at 18 weeks.

There were no significant differences between the 2 injection sites evaluated5. In another open label pilot study, 30 patients with off foot dystonia were treated with Botox. The selection of muscles was based on foot posture and included muscles like tibialis anterior, tibialis posterior, gastrocnemius, FDL, and EHL. The muscles were injected with a median dose of 40 units in each 
muscle. Dystonia was evaluated using a quantitative rating scale and all Patients showed an improvement in their foot posturing [6].

\section{Botulinum in cervical dystonia in PD}

Cervical dystonia can occur as a manifestation of PD or secondary to levodopa. Anterocollis is the most common dystonia in PD or MSA. Cervical dystonia (CD) is a focal dystonia that causes abnormal postures of the head, neck and shoulders. Class A evidence has established botulinum toxin treatment as an effective means to control the symptoms of CD. Anterocollis in PD may respond to botulinum toxin injections as used for other patterns of cervical dystonia [7]. In a prospective, multicenter, double-blind, placebo-controlled trial, subjects were randomized to one of three arms: placebo, In botulinum toxin A $120 \mathrm{U}$ and 240 Units. The primary efficacy outcome measure was change in TWSTRS score from baseline to Week 4. There was continued improvement at Week 8 and at the final visit in comparison to baseline [8]. In another study forty consecutive patients with idiopathic CD were studied. As outcome measures, Tsoi scores, VAS scores and patients' subjective evaluations were assessed at the first visit, after 12 weeks and one year.

Ten patients received injections with Botox and 11 with Dysport with a median (converted) dose of $375 \mathrm{MU}$. The muscles that were most frequently added to the muscles selected for treatment were the Splenius (SPL), the semispinalis (SESP), the Levator Scapulae (LS) and the trapezius (TPZ) muscles. The mean Tsui score in these patients improved from a baseline score of 11.2 to 10.3 after 12 weeks ( $8 \%$ improvement). After one year of treatment the Tsui scores had significantly improved to $9.1(18.8 \%$ improvement, $\mathrm{p}<0.01)$. The subjective scores also significantly improved after 12 weeks $(\mathrm{p}<0.01)$ and even further after one year $(\mathrm{p}<0.001)$ of treatment [9].

Table 1: Showing summary of studies on botulinum injection in camptochormia.

\begin{tabular}{|c|c|c|c|c|c|}
\hline Author & Patients & $\begin{array}{c}\text { Duration of } \\
\text { camptocormia }\end{array}$ & $\begin{array}{c}\text { Total toxin dose per injection } \\
\text { cycle }\end{array}$ & Ruscles \\
\hline Von Coelln, et al. & 4 & $1-3$ years & $\begin{array}{c}1000-3000 \mathrm{Mu} \text { abobotulinum } \\
\text { toxin A }\end{array}$ & $\begin{array}{c}\text { Improved at } 2 \text { weeks= } 1 \\
\text { Improved at } 6 \text { weeks= } 1 \text { No } \\
\text { improvement= } 1 \text { Worsening= } 1\end{array}$ & $\begin{array}{c}\text { Rectus abdominus, } \\
\text { External oblique }\end{array}$ \\
\hline Wijemanne, et al. & 1 & 2 years & $400 \mathrm{Mu}$ On a botulinum toxin A & Bilateral Iliopsoas \\
\hline Colosimo, et al. & 2 & NA & $800 \mathrm{MU}$ On a botulinum A & No response \\
\hline
\end{tabular}

Role of botulinum in camptocormia and PISA syndrome: for efficacy of botulinum toxin in the treatment of axial Based on the small studies and variable responses, there is insufficient data for the use of toxin in camptocormia. Summary of studies is given below in Table 1. Interestingly, evidence postural abnormalities in PD is greater for Pisa syndrome than camptocormia shown in Table 2 below [10].

Table 2: Showing the summary of studies on effect of botulinum injection in PISA syndrome.

\begin{tabular}{|c|c|c|c|c|c|}
\hline Author & Patients & Duration of Pisa syndrome & Total units of toxin & Muscles \\
\hline Tassorelli, et al. & 13 & 3.1 years & $50-175$ U xeomin & $\begin{array}{c}\text { Retus abdominis, IL, } \\
\text { Paraspinals }\end{array}$ & $\begin{array}{c}\text { Lateral flexion at } 3 \\
\text { months. }\end{array}$ \\
\hline Bonanni, et al. & 9 & $1-4$ years & $500 \mathrm{Mu}$ dysport & Bilateral Paraspinals \\
\hline
\end{tabular}

\section{Botulinum toxin in sialorrhea in PD}

Sialorrhea occurs in 32 to $74 \%$ of PD patients. Sialorrhea is classified as primary or secondary. Primary sialorrhea occurs when there is excessive production of saliva, while secondary sialorrhea is the result of disorders of the coordinated activity of the orofacial and palate lingual muscles decreasing the clearance of saliva. Research has shown that saliva production is lower in PD patients compared to healthy controls and that sialorrhea is of a secondary nature. BoNT as a possible treatment for sialorrhea was first proposed by Bushara, et al. [11]. In a review of 12 studies where the drooling score and drooling frequency score (DS-DF), the Visual Analogue Scale (VAS) and cotton-roll weight were the most frequently used methods of evaluation. BoNT type-A was tested in the range of 64-450 U. BoNT type-B was tested in the range of 1500-3500. For B type the best results were seen at the higher dose (3500 U). Mancini et al. and other several the studies reported a positive effect of BoNT on sialorrhea ranging from $50-100 \%$ of the patients with duration of the effect varied from 1 to 6 months [12].

\section{Blepharospasm and botulinum toxin}

Blepharospasm is a focal dystonia characterized by involuntary, intermittent, or persistent forceful eyelid closure due to spasmodic contractions of the orbicularis muscles. Benign essential blepharospasm describes the involuntary contractions of only the orbital and periorbital muscles. However, some patients may also have spasm of other facial, oromandibular, pharyngeal, laryngeal, or cervical muscles, which is a form of cranio-cervical dystonia called Meigs syndrome. Blepharospasm typically begins in the fifth to seventh decade of life and is more common in women. It occurs in more advanced stages of PD but can also occur in atypical Parkinsonism and is often associated with apraxia of eyelid opening, defined as an intermittent inability to voluntarily open 


\section{Open Access Journal of Neurology \& Neurosurgery}

the eyelids due to levator inhibition, abnormal contraction of the pretarsal orbicularis oculi, or eyelid freezing. BoNT has a longstanding history in the treatment of blepharospasm and is considered a first-line therapy. In an evidenced-based review of the current clinical data available, it was concluded that Onabotulinumtoxin A and Incobotulinumtoxin A are effective in the treatment of blepharospasm (level A recommendation) and Abobotulinumtoxin $\mathrm{A}$ is probably effective (level B recommendation). There were no quality studies to confirm the efficacy of Rimabotulinumtoxin B contributing to a level U the efficacy of Rimabotulinumtoxin B contributing to a level $U$ in Table 3.

\begin{tabular}{|c|c|}
\hline Disorder & Level of evidence \\
\hline Cervical dystonia & Level A recommendation \\
\hline $\begin{array}{l}\text { Blepharospasm and eyelid } \\
\text { apraxia }\end{array}$ & Level A recommendation \\
\hline Focal hand dystonia & Level B recommendation \\
\hline Laryngeal dystonia & Level C recommendation \\
\hline Lower extremity dystonia & Level U recommendation \\
\hline Camptocormia & Level U recommendation \\
\hline Oromandibular dystonia & Level C recommendation \\
\hline Sialorrhea & Level B recommendation \\
\hline
\end{tabular}

\section{References}

1. Jankovic J (2004) Botulinum toxin in clinical practice. J Neurol Neurosurg Psychiatry 75(7): 951-957.

2. Persaud R, Garas G, Silva S, Stamatoglou C, Chatrath P, et al. (2013) An evidence-based review of botulinum toxin (Botox) applications in non-cosmetic head and neck conditions. JRSM Short Rep 4(2): 10.

3. Mills R, Bahroo L, Pagan F (2015) An Update on the Use of Botulinum Toxin Therapyin Parkinson's Disease, Curr Neurol Neurosci Rep15(1): 511

4. Gupta AD, Renuka Visvanathan R (2016) Botulinum toxin for foot dystonia with Parkinson's disease having deep brain stimulation A case series and a pilot study. J Rehabil Med 48(6): 559-662.

5. Rieu I, Degos B, Castelnovo G, Vial C, Durand E, Pereira B, et al. (2018) Incobotulinum toxin A in Parkinson's disease with foot dystonia: A double blind randomized trial. Parkinsonism Relat Disord 46: 9-15.

6. Pacchetti C, Albani, G, Martignoni E, Godi L, Alfonsi E, Nappi G (1995) Off painful dystonia in Parkinson's disease treated with botulinum toxin. Mov Disord 10(3): 333-336.

7. Papapetropoulos, Carlos Singer (2006) Cervical dystonia as a presenting symptom of Parkinson's disease. Parkinsonism \& Related Disorders 12(8): $514-516$.

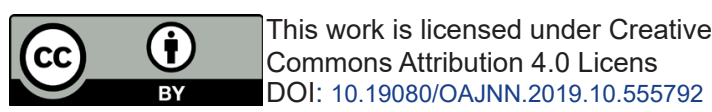

recommendation $[13,14]$. Summary: Parkinson's disease is a degenerative disorder with its complications extending much beyond the motor features. In many cases pharmacological therapies are of little help. Botulinum injection seems quite cost effective, easily available worldwide, effective in counteracting and improving many of the problems linked to Parkinson's disease. Common disorders treated with botulinum toxin and level of evidence for the safety and efficacy of botulinum toxin use. Evidence of its use for various indications in summarized

ious indications in Parkinson's disease.

8. Sheffield JK, Jankovic J (2007) Botulinum toxin in the treatment of tremors, dystonias, sialorrhea and other symptoms associated with Parkinson's disease. Expert Rev Neur 7(6): 637-647.

9. Cynthia L, Jankovic J, Truong DD, Hanschmann A, Grafe S, et al. (2011) Efficacy and safety of incobotulinumtoxinA (NT 201, XEOMIN ${ }^{\circledR}$, botulinum neurotoxin type $\mathrm{A}$, without accessory proteins) in patients with cervical dystonia. J Neurol Sci 308 (1-2): 103-109.

10. Nijmeijer , Koelman , Standaar, Postma, Tijssen (2013) Cervical dystonia: Improved treatment response to botulinum toxin after referralto a tertiary centre and the use of polymyography. Parkinsonism and Related Disorders 19(5): 533-538.

11. Bushara KO (1997) Sialorrhea in amyotrophic lateral sclerosis: a hypothesis of a new treatment: botulinum toxin A injections of the parotid glands. Med Hypotheses 48: 337-339.

12. Egevad G, Petkova VY, Vilholm OJ (2014) Sialorrhea in Patients with Parkinson's disease: Safety and Administration of Botulinum Neurotoxin. J Parkinson's Disease 4(3): 321-326.

13. Hallett M, Evinger C, Jankovic J, Stacy M (2008) Update on blepharospasm: report from the BEBRF International Workshop. Neurology 71(16): 1275-1282.

14. Shukla W, Aparna, Malaty, Irene (2017) Botulinum Toxin Therapy for Parkinson's disease. Seminars in Neurology 37(2): 193-204.

\begin{tabular}{l} 
Your next submission with Juniper Publishers \\
will reach you the below assets \\
- Quality Editorial service \\
- Swift Peer Review \\
- Reprints availability \\
- E-prints Service \\
- Manuscript Podcast for convenient understanding \\
- Global attainment for your research \\
- Manuscript accessibility in different formats \\
( Pdf, E-pub, Full Text, Audio) \\
- Unceasing customer service \\
Track the below URL for one-step submission \\
https://juniperpublishers.com/online-submission.php \\
\hline
\end{tabular}

